Gut and Liver, Vol. 9, No. 6, November 2015, pp. 741-749

\title{
The Risk of Metachronous Advanced Colorectal Neoplasia Rises in Parallel with an Increasing Number of High-Risk Findings at Baseline
}

\author{
Seung Min Lee*, Jeong Hwan Kim*, In Kyung Sung*, and Sung Noh Hong ${ }^{\dagger}$ \\ ${ }^{*}$ Department of Internal Medicine, Konkuk University School of Medicine, and ${ }^{\dagger}$ Department of Medicine, Samsung Medical Center, \\ Sungkyunkwan University School of Medicine, Seoul, Korea
}

Background/Aims: Colorectal adenomas that are $\geq 10$ $\mathrm{mm}$ have villous histology or high-grade dysplasia, or that are associated with $\geq 3$ adenomas are considered high-risk for metachronous advanced neoplasia. We evaluated the cumulative incidence of metachronous advanced neoplasia according to the total number of high-risk findings detected on baseline colonoscopy. Methods: This was a retrospective cohort study performed in 862 patients who underwent removal of colorectal adenomas between 2005 and 2009. At least one surveillance colonoscopy had been conducted at Konkuk University Medical Center, Seoul, Korea. Results: The cumulative incidence of metachronous advanced neoplasia in patients with $0,1,2$, and 3-4 high-risk findings at 1 year were $0.7 \%, 1.3 \%, 2.8 \%$, and $8.0 \%$; at 3 years, those were $5.9 \%, 11.9 \%, 15.5 \%$, and $24.7 \%$; and at 5 years, those were $8.5 \%, 18.7 \%, 26.3 \%$, and $37.2 \%$, respectively. In a multivariate model, the risk of metachronous advanced neoplasia was significantly higher for the multiple high-risk findings group when compared with the 0 high-risk findings group (1 high-risk (+): hazard ratio, 1.86 [95\% confidence interval, 1.00-3.44]; 2 high-risk (+): 1.84 [0.88-3.84]; and 3-4 highrisk (+): 3.29 [1.54-7.01]; $\left.p_{\text {trend }}=0.020\right)$. Conclusions: The presence of overlapping multiple high-risk findings was associated with an increased risk of advanced neoplasia during surveillance. (Gut Liver 2015;9:741-749)

Key Words: Colorectal neoplasia; Colonoscopy; Surveillance; Polypectomy

\section{INTRODUCTION}

Postpolypectomy colonoscopic surveillance is the standard of care following the removal of colorectal neoplasms to detect a new or missed lesion and prevent colorectal cancer. ${ }^{1-5}$ Due to the increased use of screening colonoscopy, increasing numbers of adenomas are being diangosed, making postpolypectomy surveillance a major part of endoscopic practice. ${ }^{1}$ Previous studies have reported that certain colonoscopic findings, including the size of an adenoma $\geq 1 \mathrm{~cm}$, high-grade dysplasia, villous histology, or 3 or more adenomas, are associated with an increased risk of metachronous advanced neoplasia. ${ }^{1-5}$ Therefore, current practice guidelines recommend that patients with any of those high-risk findings have a follow-up colonoscopy in 3 years. ${ }^{1-6}$

Importantly, each individual high-risk finding has demonstrated an independent association with an increased risk of metachronous advanced neoplasia, suggesting the possibility that patients with multiple high-risk findings are at higher risk than patients with a single finding. ${ }^{6-14}$ In previous colonoscopybased studies, the probability of subsequent advanced adenomas in patients with multiple high-risk findings was higher than in patients with no or few high-risk findings.

There is no published literature on the risk for metachronous advanced neoplasia according to the accumulated number of high-risk findings on baseline colonoscopy. Therefore, the aim of this study was to estimate the cumulative incidence rate of metachronous advanced neoplasia according to the accumulated number of high-risk findings detected on baseline colonoscopy.

\section{MATERIALS AND METHODS}

\section{Study population}

Between August 2005 and July 2009, a total of 1,597 patients underwent colonoscopy with polyp removal and completed one or more surveillance colonoscopies at Konkuk University Medical Center in Seoul, Korea. We constructed cohorts using data stripped of identifiers from the centralized electronic medical

Correspondence to: Sung Noh Hong

Department of Medicine, Samsung Medical Center, Sungkyunkwan University School of Medicine, 81 Irwon-ro, Gangnam-gu, Seoul 06351, Korea

Tel: +82-2-3410-3409, Fax: +82-2-3410-6983, E-mail: sungnoh.hong@samsung.com

Received on June 1, 2014. Revised on September 29, 2014. Accepted on October 6, 2014. Published online May 13, 2015

pISSN 1976-2283 eISSN 2005-1212 http://dx.doi.org/10.5009/gnl14210

() This is an Open Access article distributed under the terms of the Creative Commons Attribution Non-Commercial License (http://creativecommons.org/licenses/by-nc/4.0) which permits unrestricted non-commercial use, distribution, and reproduction in any medium, provided the original work is properly cited. 
record system. Exclusion criteria were as follows: (1) patients without a histologically confirmed adenoma on baseline colonoscopy; (2) incomplete polyp removal (except small hyperplasic polyps in the rectosigmoid area or typical inflammatory pseudo-polyps); (3) follow-up colonoscopy that was performed within 6 months of the baseline colonoscopy; (4) follow-up colonoscopy that was performed 5 years after the baseline colonoscopy; (5) unavailability of the data on the size, number, and histopathology of removed polyps; (6) incomplete colonoscopy, such as failed cecal intubation or inadequate bowel preparation; (7) patients diagnosed with invasive cancer on baseline colonoscopy; (8) patients with polyposis syndrome, hereditary cancer syndrome, or inflammatory bowel disease; and (9) patients with a history of colorectal resection (except appendectomy).

\section{Colonoscopy and definitions}

All colonoscopies were performed with either a high-definition CF-H260AI (Olympus, Tokyo, Japan) or an EC-3490Fi (Pentax, Tokyo, Japan). The size, number, and location of colorectal lesions were described by the endoscopist during the colonoscopy. All colorectal lesions were evaluated by an experienced pathologist and classified according to World Health Organization (WHO) criteria. ${ }^{15}$ An advanced adenoma was defined as an adenoma $\geq 10 \mathrm{~mm}$, with villous histology (more than $25 \%$ villous features), or high-grade dysplasia. Invasive cancer was defined as the invasion of an adenocarcinoma through the muscularis mucosa into the submucosa. ${ }^{15}$ Advanced neoplasia consisted of an advanced adenoma or invasive cancer.

High-risk finding referred to the findings associated with an increased risk of metachronous advanced neoplasia, including adenoma size $\geq 10 \mathrm{~mm}$, villous histology, high-grade dysplasia, or $\geq 3$ adenomas. $^{1-6}$

\section{Postpolypectomy colonoscopic surveillance schedule}

During the baseline colonoscopy, adenomas $\leq 5 \mathrm{~mm}$ were removed using cold or hot biopsies; adenomas $>5 \mathrm{~mm}$ were resected using snare polypectomies with or without submucosal injections. Large sessile adenomas $>2 \mathrm{~cm}$ were removed using endoscopic piecemeal mucosal resections or submucosal dissection. In any patient who underwent a piecemeal resection of a large sessile adenoma or a suspected incomplete polyp resection, a follow-up colonoscopy was performed within 6 months to assess the need for additional polypectomy. In those cases, the follow-up interval was calculated from the date of this second "clearing" colonoscopy, and all adenomas detected at the clearing colonoscopy were considered to have been missed on the initial colonoscopy and were thus considered baseline findings for analysis. After baseline colonoscopy and polypectomy, each subject was informed of their surveillance schedule. Patients with advanced adenoma or multiple adenomas were assigned to a follow-up colonoscopy in 1 year; patients with a single tubular adenoma $<1 \mathrm{~cm}$ were assigned to a surveillance colonoscopy in 3 years. The surveillance schedule was open to modification at the physician's discretion based on age, family history, comorbidities, and patient preference.

\section{Endpoint measurement}

Metachronous advanced neoplasm was defined as any histologically confirmed advanced adenoma or invasive cancer detected during the surveillance colonoscopy. The endpoint was defined as the time when a surveillance colonoscopy diagnosed a metachronous advanced neoplasia.

\section{Statistical analysis}

Continuous variables are expressed as mean \pm standard deviation, while categorical variables are presented as absolute values and percentages. The differences between continuous variables were analyzed using the unpaired Student t-test; differences between greater than three continuous variables were analyzed using analysis of variance. Differences between categorical variables were analyzed by the chi-square test or Fisher exact test, as appropriate. The cumulative hazard of the recurrence of advanced colorectal neoplasia stratified according to the number of high-risk findings on baseline colonoscopy was determined using the Kaplan-Meier method. Differences between survival curves were tested using the log-rank test. The hazard ratios (HRs) and 95\% confidence intervals (CIs) of the recurrence of metachronous advanced neoplasia based on the number of highrisk findings were computed using the Cox proportional hazard model. To examine potential confounders for the recurrence of metachronous advanced neoplasia, multivariate models were adjusted for age, gender, timing of first surveillance colonoscopy, and number of surveillance colonoscopies performed during the study period. Statistical analysis was performed using SPSS version 12.0K (SPSS Inc., Chicago, IL, USA).

\section{RESULTS}

Of the 1,597 patients that underwent a colonoscopy with polyp removal and at least one surveillance colonoscopy, 735 were excluded due to a lack of histologically confirmed adenoma on baseline colonoscopy $(n=180)$, incomplete polyp removal $(n=32)$, follow-up colonoscopy in $<6$ months $(n=46)$, or $>5$ years $(n=23)$, inaccurate endoscopy or pathology reports $(n=135)$, incomplete colonoscopy $(n=199)$, invasive cancer detected on baseline colonoscopy $(n=105)$, polyposis syndrome $(n=5)$, inflammatory bowel disease $(n=42)$, or history of colorectal resection $(n=18)$ (Fig. 1).

The baseline clinical characteristics of the 862 patients ultimately enrolled in this study are shown in Table 1. On baseline colonoscopy, 1-2 adenomas were removed in 567 patients (65.8\%), $\geq 3$ adenomas were removed in 295 patients (34.2\%), an adenoma $\geq 1 \mathrm{~cm}$ was removed in 194 patients (22.5\%), a tubulovillous or villous adenoma was removed in 90 patients (10.4\%), 


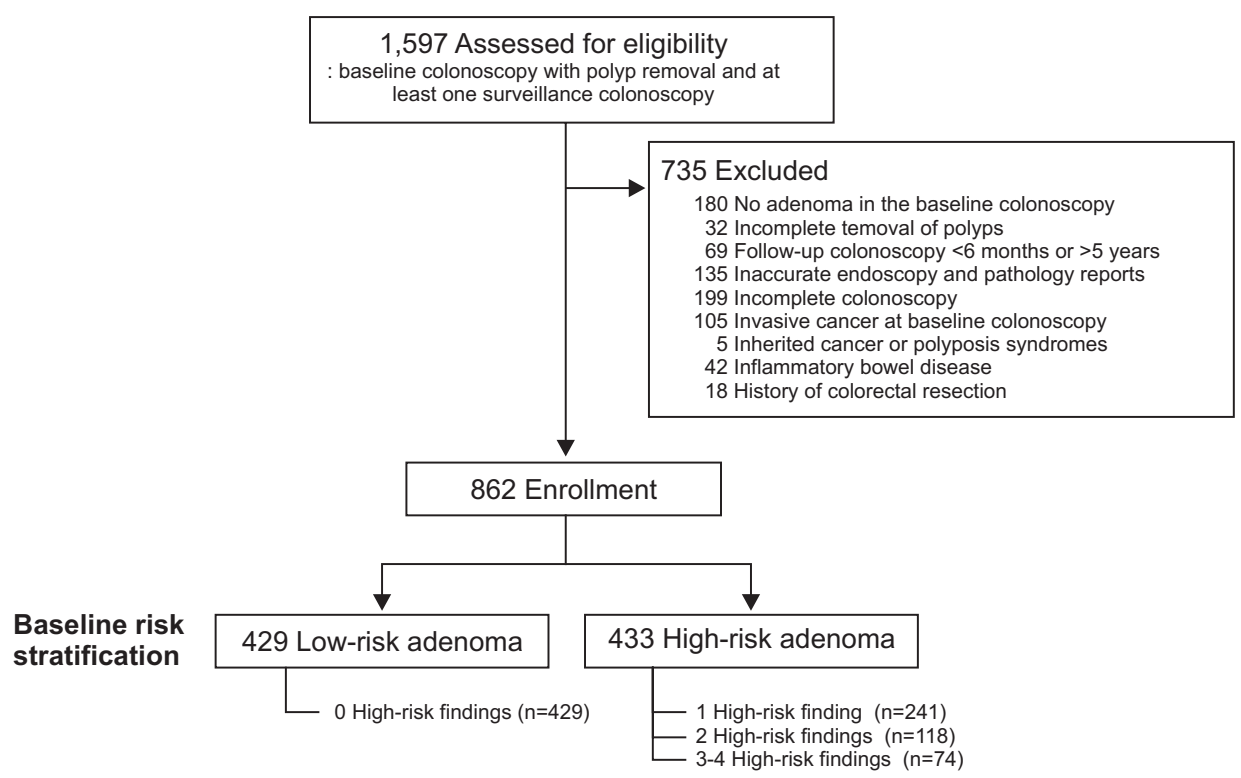

Fig. 1. Diagram of study enrollment.

Table 1. Patient Characteristics according to the Number of High-Risk Findings at Baseline

\begin{tabular}{|c|c|c|c|c|c|c|}
\hline \multirow{2}{*}{ Characteristic } & \multirow{2}{*}{$\begin{array}{c}\text { Total } \\
(n=862)\end{array}$} & \multicolumn{4}{|c|}{ No. of high-risk findings* } & \multirow{2}{*}{ p-value } \\
\hline & & $0(\mathrm{n}=429)$ & $1(\mathrm{n}=241)$ & $2(\mathrm{n}=118)$ & $3-4(\mathrm{n}=74)$ & \\
\hline Age, yr & $61.5 \pm 10.4$ & $59.9 \pm 10.2$ & $61.5 \pm 11.0$ & $61.7 \pm 10.3$ & $65.5 \pm 8.6$ & $<0.001$ \\
\hline$<50$ & $118(13.7)$ & $64(14.9)$ & $38(15.8)$ & $13(11.0)$ & $3(4.1)$ & 0.01 \\
\hline $50-59$ & $250(29.0)$ & $139(32.4)$ & $56(23.2)$ & $38(32.2)$ & $17(23.0)$ & \\
\hline $60-69$ & $291(33.8)$ & $142(33.1)$ & $83(34.4)$ & $39(33.1)$ & $27(36.5)$ & \\
\hline$\geq 70$ & $203(23.5)$ & $84(19.6)$ & $64(26.6)$ & $28(23.7)$ & 27 (36.5) & \\
\hline \multicolumn{7}{|l|}{ Sex } \\
\hline Male & $632(73.3)$ & $298(69.5)$ & $186(77.2)$ & $89(75.4)$ & 59 (79.7) & 0.08 \\
\hline Female & $230(26.7)$ & $131(30.5)$ & $55(22.8)$ & $29(24.6)$ & $15(20.3)$ & \\
\hline No. of adenomas & $2.6 \pm 2.3$ & $1.3 \pm 0.5$ & $3.5 \pm 2.2$ & $3.9 \pm 3.1$ & $4.7 \pm 3.7$ & $<0.001$ \\
\hline 1 or 2 & $567(65.8)$ & $429(100)$ & $77(32.0)$ & $41(34.7)$ & $20(27.0)$ & $<0.001$ \\
\hline$\geq 3$ & $295(34.2)$ & 0 & $164(68.0)$ & $77(65.3)$ & $54(73.0)$ & \\
\hline Size of the largest adenoma, $\mathrm{mm}$ & $9.0 \pm 6.6$ & $5.7 \pm 2.4$ & $8.6 \pm 5.0$ & $14.8 \pm 7.4$ & $19.9 \pm 9.0$ & $<0.001$ \\
\hline$\leq 10$ & $668(77.5)$ & $429(100)$ & $199(82.6)$ & $34(28.8)$ & $6(8.1)$ & $<0.001$ \\
\hline$>10$ & $194(22.5)$ & 0 & $42(17.4)$ & $84(71.2)$ & $68(91.9)$ & \\
\hline \multicolumn{7}{|l|}{ Histology of adenoma } \\
\hline Tubular adenoma & 772 (89.6) & $429(100)$ & $235(97.5)$ & $87(73.7)$ & $21(28.4)$ & $<0.001$ \\
\hline Tubulovillous or villous adenoma & $90(10.4)$ & 0 & $6(2.5)$ & $31(26.3)$ & $53(71.6)$ & \\
\hline \multicolumn{7}{|l|}{ Dysplasia grade } \\
\hline Low-grade & $729(84.6)$ & $429(100)$ & $212(88.0)$ & $67(56.8)$ & $14(18.9)$ & $<0.001$ \\
\hline High-grade & $133(15.4)$ & 0 & $29(12.0)$ & $44(37.3)$ & $60(81.1)$ & \\
\hline Nonadvanced adenoma & $593(68.8)$ & $429(100)$ & $164(68.0)$ & 0 & 0 & $<0.001$ \\
\hline Advanced adenoma $^{\dagger}$ & $269(31.2)$ & 0 & $77(32.0)$ & $118(98.3)$ & $74(100)$ & \\
\hline
\end{tabular}

Data are presented as mean \pm SD or number (\%).

*High-risk findings of baseline colonoscopy were defined as follows: adenoma with villous histology, high-grade dysplasia, size $>10 \mathrm{~mm}$, or 3 or more adenomas; ${ }^{\dagger}$ Advanced adenoma was defined as adenoma with villous histology, high-grade dysplasia, or size $>10 \mathrm{~mm}$. 
and an adenoma with high-grade dysplasia was removed in 133 patients (15.4\%). At baseline, the numbers of patients with advanced and nonadvanced adenomas were 269 (31.2\%) and 593 (68.8\%), respectively. The baseline number of patients with 0 , 1, 2, 3, and 4 high-risk findings were 429 (49.8\%), 241 (28.0\%), 118 (13.7\%), 61 (7.1\%), and 13 (1.5\%), respectively.

\section{Postpolypectomy surveillance}

Results of postpolypectomy surveillance are shown in Table 2. The mean follow-up duration of enrolled patients was $44.2 \pm 20.9$ months and the mean number of surveillance colonoscopies during the study period was $1.2 \pm 0.6$. Although the number of surveillance colonoscopies showed a trend towards increasing tendency as the number of high-risk findings increased, there were no significant intergroup differences in terms of follow-up duration nor number of surveillance colonoscopies.

During surveillance colonoscopies, 454 patients (52.7\%) had one or more colorectal neoplasia and 68 patients (7.9\%) had one or more advanced neoplasia, of which three $(0.3 \%)$ were invasive cancers. Of the three invasive cancers diagnosed during the follow-up period, two patients underwent diagnostic colonoscopies at 24 and 30 months after the initial baseline colonoscopy, and one asymptomatic patient underwent a routine surveillance colonoscopy 36 months after the baseline colonoscopy.
There were no complications resulting in serious morbidity or mortality during either baseline or surveillance colonoscopies. Although five cases of colonic perforation and seven cases of bleeding after polypectomy were reported, all of which were treated medically.

\section{Cumulative incidence of metachronous colorectal neo- plasms}

Table 3 shows the cases of advanced neoplasia detected in any colonoscopy performed during the study period. The cumulative incidence rates of advanced neoplasia were 1.7\%, $5.4 \%, 10.2 \%$, and $16.1 \%$ at the 1-, 2-, 3-, and 5-year follow-up exams, respectively. We estimated the cumulative incidence of advanced neoplasia in patients with baseline low-risk and highrisk adenomas per the current guidelines (Fig. 2). The cumulative incidence rates of advanced neoplasia in patients with lowrisk adenomas were $0.7 \%, 3.3 \%, 5.9 \%$, and $8.5 \%$ at the $1-, 2-$, 3-, and 5-year follow-up exams, respectively; incidence rates of patients with high-risk adenomas were $2.8 \%, 7.6 \%, 14.9 \%$, and 23.9\% at the 1-, 2-, 3-, and 5-year follow-up exams, respectively. Cumulative incidence rates of advanced neoplasia were significantly different between low-risk and high-risk patients $(\mathrm{p}<0.001)$. Current guidelines recommend follow-up colonoscopy in 5 years for patients with a low-risk adenoma and in

Table 2. Postpolypectomy Surveillance Results according to the Number of High-Risk Findings at Baseline

\begin{tabular}{|c|c|c|c|c|c|c|}
\hline & \multirow{2}{*}{$\begin{array}{c}\text { Total } \\
(n=862)\end{array}$} & \multicolumn{4}{|c|}{ No. of high-risk findings* } & \multirow{2}{*}{$\mathrm{p}$-value } \\
\hline & & $0(\mathrm{n}=429)$ & $1(\mathrm{n}=241)$ & $2(\mathrm{n}=118)$ & $3-4(n=74)$ & \\
\hline Total follow-up duration, mo & $44.2 \pm 20.9$ & $45.3 \pm 19.7$ & $44.9 \pm 22.0$ & $39.6 \pm 22.1$ & $43.0 \pm 21.7$ & 0.06 \\
\hline Timing of first follow-up colonoscopy, mo & $25.3 \pm 15.4$ & $27.1 \pm 15.2$ & $25.3 \pm 15.3$ & $21.7 \pm 14.3$ & $20.9 \pm 17.0$ & $<0.001$ \\
\hline No. of follow-up colonoscopies during study period & $1.2 \pm 0.6$ & $1.2 \pm 0.5$ & $1.3 \pm 0.6$ & $1.4 \pm 0.7$ & $1.4 \pm 0.7$ & 0.06 \\
\hline 1 & $650(75.4)$ & $335(78.1)$ & $181(75.1)$ & $81(68.6)$ & 53 (71.6) & 0.23 \\
\hline 2 & $163(18.9)$ & $78(18.2)$ & $44(18.3)$ & $27(22.9)$ & $14(18.9)$ & \\
\hline 3 & $37(4.3)$ & $11(2.6)$ & $14(5.8)$ & $7(6.0)$ & $5(6.8)$ & \\
\hline 4 & $11(1.3)$ & $5(1.2)$ & $1(0.4)$ & $3(2.6)$ & $2(2.7)$ & \\
\hline 5 & $1(0.1)$ & 0 & $1(0.4)$ & 0 & 0 & \\
\hline \multicolumn{7}{|l|}{ Follow-up colonoscopy findings } \\
\hline Colorectal neoplasia (-) & $407(47.2)$ & $229(53.4)$ & $101(41.9)$ & $51(43.2)$ & $26(35.1)$ & \\
\hline Colorectal neoplasia (+) & $455(52.8)$ & $200(46.6)$ & $140(58.1)$ & $67(56.8)$ & $48(64.9)$ & 0.002 \\
\hline Multiple ( $\geq 3$ ) colorectal neoplasias & $106(12.3)$ & $42(9.8)$ & $28(11.6)$ & $20(16.9)$ & $16(21.6)$ & 0.01 \\
\hline Advanced neoplasia $^{\dagger}$ & $68(7.9)$ & $19(4.4)$ & $22(9.1)$ & $13(11.0)$ & $14(18.9)$ & $<0.001$ \\
\hline$>1 \mathrm{~cm}$ in size & 43 & 10 & 16 & 9 & 8 & \\
\hline Tubulovillous or villous adenoma & 13 & 3 & 3 & 1 & 6 & \\
\hline High-grade dysplasia & 29 & 10 & 11 & 5 & 3 & \\
\hline Located in the proximal colon $^{\ddagger}$ & 35 & 12 & 8 & 6 & 9 & \\
\hline Invasive cancer & 3 & 1 & 1 & 1 & 0 & \\
\hline
\end{tabular}

Data are presented as mean \pm SD or number $(\%)$.

*High-risk findings of baseline colonoscopy were defined as follows: adenoma with villous histology, high-grade dysplasia, size $>10 \mathrm{~mm}$, or 3 or more adenomas; ${ }^{\dagger}$ Advanced neoplasia consisted of an advanced adenoma (adenoma with villous histology, high-grade dysplasia, or size $>10 \mathrm{~mm}$ ) or invasive cancer; ${ }^{\ddagger}$ The proximal colon was defined as the portion of the colon proximal to the splenic flexure. 
Table 3. Occurrence of Advanced Neoplasia Based on the Timing of Follow-Up Colonoscopy and the Cumulative Incidence Rates of Advanced Neoplasia according to the Number of High-Risk Findings at Baseline

\begin{tabular}{|c|c|c|c|c|c|c|c|c|c|c|c|c|}
\hline \multirow[b]{2}{*}{$\begin{array}{l}\text { Follow- } \\
\text { up, yr }\end{array}$} & \multicolumn{3}{|c|}{0 High-risk finding* $(n=429)$} & \multicolumn{3}{|c|}{1 High-risk finding* $(n=241)$} & \multicolumn{3}{|c|}{2 High-risk findings* $(\mathrm{n}=118)$} & \multicolumn{3}{|c|}{ 3-4 High-risk findings* $(n=74)$} \\
\hline & $\begin{array}{l}\text { No. } \\
\text { at risk }\end{array}$ & $\begin{array}{c}\text { Advanced } \\
\text { neoplasia, } \\
\mathrm{n}^{\dagger}\end{array}$ & $\begin{array}{c}\text { Cumulative } \\
\text { incidence, } \\
\%\end{array}$ & $\begin{array}{l}\text { No. } \\
\text { at risk }\end{array}$ & $\begin{array}{c}\text { Advanced } \\
\text { neoplasia, } \\
\mathrm{n}^{\dagger}\end{array}$ & $\begin{array}{c}\text { Cumulative } \\
\text { incidence, } \\
\%\end{array}$ & $\begin{array}{l}\text { No. } \\
\text { at risk }\end{array}$ & $\begin{array}{c}\text { Advanced } \\
\text { neoplasia, } \\
\mathrm{n}^{\dagger}\end{array}$ & $\begin{array}{c}\text { Cumulative } \\
\text { incidence, } \\
\%\end{array}$ & $\begin{array}{l}\text { No. } \\
\text { at risk }\end{array}$ & $\begin{array}{c}\text { Advanced } \\
\text { neoplasia, } \\
\mathrm{n}^{\dagger}\end{array}$ & $\begin{array}{c}\text { Cumulative } \\
\text { incidence, } \\
\%\end{array}$ \\
\hline 1 & 429 & 3 & 0.7 & 241 & 3 & 1.3 & 118 & 3 & 2.8 & 74 & 5 & 8.0 \\
\hline 2 & 390 & 8 & 3.3 & 214 & 8 & 6.0 & 93 & 3 & 6.8 & 46 & 3 & 15.3 \\
\hline 3 & 224 & 5 & 5.9 & 114 & 6 & 11.9 & 50 & 4 & 15.5 & 27 & 3 & 24.7 \\
\hline 4 & 146 & 2 & 7.4 & 71 & 2 & 14.8 & 32 & 2 & 21.7 & 24 & 2 & 31.7 \\
\hline 5 & 101 & 1 & 8.5 & 51 & 2 & 18.7 & 20 & 1 & 26.3 & 17 & 1 & 37.2 \\
\hline
\end{tabular}

*High-risk findings of baseline colonoscopy were defined as follows: adenoma with villous histology, high-grade dysplasia, size $>10 \mathrm{~mm}$, or 3 or more adenomas; ${ }^{\dagger}$ Advanced neoplasia consisted of an advanced adenoma (adenoma with villous histology, high-grade dysplasia, or size $>10 \mathrm{~mm}$ ) or invasive cancer.

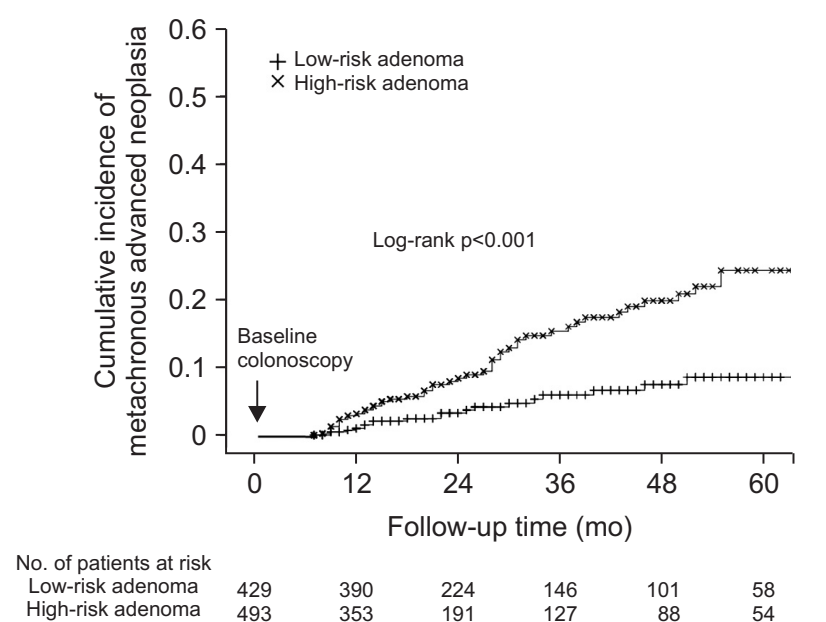

Fig. 2. Cumulative incidence rates of metachronous advanced neoplasia in low-risk and high-risk patients.

3 years for patients with a high-risk adenoma. We found the number needed to rescreen to detect one case advanced neoplasia 5 years after polypectomy was 11.7 (95\% CI, 7.1 to 32.5) in patients with low-risk adenomas and 6.7 (95\% CI, 5.0 to 10.2) in patients with high-risk adenoma.

The cumulative incidence rates of advanced neoplasia according to the number of baseline high-risk findings are shown in Table 3 and Fig. 3. The 1-year cumulative incidence rates of metachronous advanced neoplasia in patients with $0,1,2$, and 3-4 high-risk findings were 0.7\%, 1.3\%, 2.8\%, and 8.0\%, respectively; 2-year incidence rates were 3.3\%, 6.0\%, 6.8\%, and 15.3\%, respectively; 3-year incidence rates were 5.9\%, 11.9\%, 15.5\%, and 24.7\%, respectively; and 5-year incidence rates were 8.5\%, 18.7\%, 26.3\%, and 37.2\%, respectively. There was a significant difference in the cumulative incidence of metachronous advanced neoplasia between groups with different numbers of baseline high-risk finding groups $(\mathrm{p}<0.001)$. Of the patients with no high-risk findings, 212 (49.4\%) underwent their first surveillance within 2 years, and rates of advanced neoplasia were

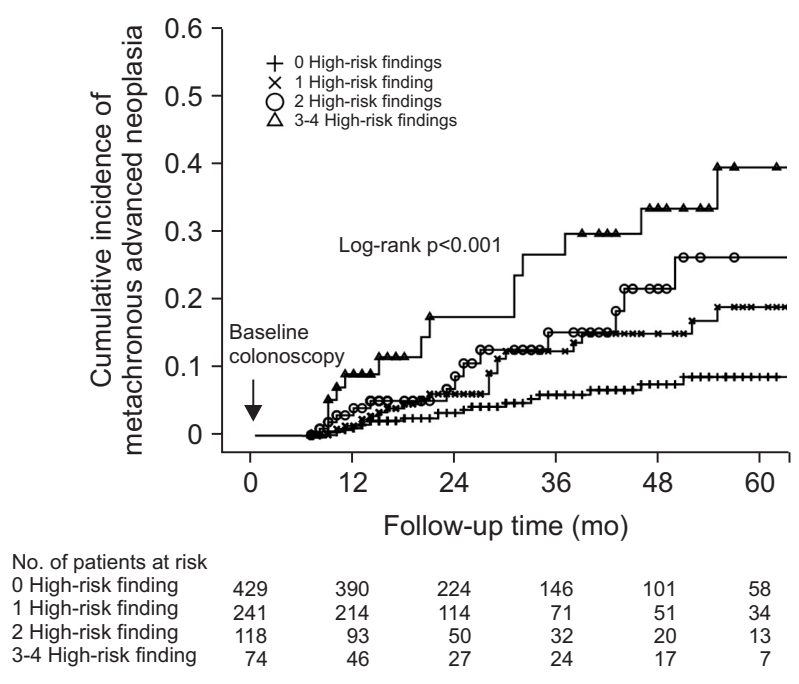

Fig. 3. Cumulative incidence of metachronous advanced neoplasia based on the number of high-risk findings at baseline.

similar irrespective of the time to first surveillance (5.7\% within 2 years vs 3.2\% at $\geq 2$ years, $p=0.248$ ). Nearly all subjects with one or more high-risk findings underwent their first surveillance within 2 years and the majority underwent repeat examinations; their rates of advanced neoplasia were also similar irrespective of the timing of the first surveillance. Numbers needed to rescreen to detect one advanced neoplasia 3 years after polypectomy in patients with 1,2 , and 3-4 high-risk findings were 8.4 (95\% CI, 5.6 to 16.8), 6.5 (95\% CI, 3.9 to 18.3), and 4.1 (95\% CI, 2.4 to 11.9 ), respectively. Notably, in the $3-4$ high-risk findings group, numbers needed to rescreen for one advanced neoplasia at 1 and 2 years were 12.5 (95\% CI, 7.1 to 54.9) and 6.6 (95\% CI, 3.9 to 20.5), respectively.

\section{Number of baseline high-risk findings as a risk factor for metachronous advanced neoplasia}

Table 4 shows the results of univariate and multivariate analyses according to the Cox proportional hazard regression model 
Table 4. Risk of Metachronous Advanced Neoplasia according to the Number of High-Risk Findings at Baseline

\begin{tabular}{|c|c|c|c|c|c|c|}
\hline & \multicolumn{3}{|c|}{ Univariate analysis } & \multicolumn{3}{|c|}{ Multivariate analysis* } \\
\hline & HR & $95 \% \mathrm{CI}$ & p-value & HR & $95 \%$ CI & p-value \\
\hline Age, yr & 1.01 & $0.98-1.03$ & 0.52 & 0.99 & $0.97-1.02$ & 0.88 \\
\hline Male sex & 1.19 & $0.69-2.06$ & 0.54 & 1.06 & $0.61-1.86$ & 0.84 \\
\hline No. of follow-up colonoscopies during study period & 0.95 & $0.69-1.32$ & 0.78 & 0.82 & $0.59-1.15$ & 0.26 \\
\hline No. of high-risk findings detected on baseline colonoscopy ${ }^{\dagger}$ & 1.67 & $1.38-2.03$ & $<0.001$ & 1.72 & $1.40-2.11$ & $<0.001$ \\
\hline
\end{tabular}

HR, hazard ratio; CI, confidence interval.

${ }^{*}$ Adjustment for age, gender, number of follow-up colonoscopies during the study period, and number of high-risk baseline findings; ${ }^{\dagger}$ High-risk baseline findings were defined as follows: adenoma with villous histology, high-grade dysplasia, size $>10$ mm, or 3 or more adenomas.

Table 5. The Association of Individual High-Risk Findings with Metachronous Advanced Colorectal Neoplasia

\begin{tabular}{|c|c|c|c|c|c|c|}
\hline & \multicolumn{3}{|c|}{ Univariate analysis } & \multicolumn{3}{|c|}{ Multivariate analysis* } \\
\hline & $\mathrm{HR}$ & $95 \% \mathrm{CI}$ & p-value & $\mathrm{HR}$ & $95 \% \mathrm{CI}$ & p-value \\
\hline Adenoma size $>10 \mathrm{~mm}$ & 1.65 & $1.61-2.34$ & 0.005 & 1.34 & $0.91-1.99$ & 0.141 \\
\hline Adenoma with villous histology & 1.82 & $1.12-2.93$ & 0.015 & 1.64 & $0.95-2.84$ & 0.078 \\
\hline High-grade dysplasia & 1.08 & $0.68-1.71$ & 0.760 & 0.74 & $0.44-1.24$ & 0.250 \\
\hline$\geq 3$ Adenomas & 2.41 & $1.70-3.42$ & $<0.001$ & 2.25 & $1.55-3.25$ & $<0.001$ \\
\hline
\end{tabular}

HR, hazard ratio; CI, confidence interval.

*Adjusted for age, gender, number of follow-up colonoscopies during the study period, adenoma size >10 mm, adenoma with villous histology, high-grade dysplasia, and $\geq 3$ adenomas.

for metachronous advanced neoplasia. After adjustment for age, gender, timing of first surveillance, and number of surveillance colonoscopies, the risk of metachronous advanced neoplasia was significantly higher in the multiple high-risk findings group compared to the no high-risk findings group (1 high-risk finding: HR, 1.86, 95\% CI, 1.00 to 3.44; 2 high-risk findings: HR, $1.84,95 \% \mathrm{CI}, 0.88$ to $3.84 ; 3-4$ high-risk findings: HR, 3.29, $95 \%$ CI, 1.54 to $7.01 ; p_{\text {trend }}=0.020$ ). In addition, when the number of high-risk findings was used as a continuous variable, the risk of metachronous advanced neoplasia increased significantly along with the number of high-risk findings (HR, 1.44; 95\% CI, 1.16 to $1.80, \mathrm{p}<0.001)$.

In addition, we analyzed the association of individual highrisk findings with metachronous advanced colorectal neoplasia using the Cox regression model (Table 5). The HR of adenoma size $>10 \mathrm{~mm}$, adenoma with villous histology, high-grade dysplasia, and $\geq 3$ adenomas is 1.65 (95\% CI, 1.61 to 2.34), 1.82 (95\% CI, 1.12 to 2.93), 1.08 (95\% CI, 0.68 to 1.71 ), and 2.41 (95\% CI, 1.70 to 3.42 ), respectively. Using multivariate analysis adjusted with age, gender, number of follow-up colonoscopies during the study period, and individual high-risk findings, only $\geq 3$ adenomas showed a statistically significant association (HR, 2.25; 95\% CI, 1.55 to 3.25).

\section{DISCUSSION}

In clinical practice, the adherence to practice guidelines is low and many physicians recommend a shorter surveillance interval after colonoscopic polypectomy. ${ }^{16-18}$ Many reasons may contribute to poor adherence to guidelines, including concerns about interval cancer after colonoscopy. ${ }^{19-21}$ Since the publications of the National Polyp Study and the Funen Adenoma Follow-up Study, ${ }^{19,22-24}$ a 3-year follow-up colonoscopy is recommended for patients with high-risk adenoma and a 5- to 10-year followup examination for patients at lower risk, i.e., 1 or 2 small tubular adenomas without high-grade dysplasia. ${ }^{1-6}$ Notably, the National Polyp Study excluded patients with sessile adenomas with bases larger than $3 \mathrm{~cm}$ and provided individualized followup evaluations, ${ }^{19}$ while the Funen Adenoma Follow-up Study included only patients with pedunculated and small sessile tubular/tubulovillous adenomas. ${ }^{20}$ The excluded patients with large sessile adenomas were at a high risk of additional highrisk findings, including multiple adenomas and advanced pathology, such as a significant villous component or high-grade dysplasia. $^{1-6}$

To the best of our knowledge, this is the first analysis of the risk of metachronous advanced colorectal neoplasia in patients with multiple high-risk findings detected on baseline colonoscopy. In this study, we found that the risk of metachronous advanced neoplasia increased significantly along with the number of baseline high-risk findings. Using the current guidelines' risk stratification scheme (high-risk vs low-risk adenoma), ${ }^{1-6,19,21,22}$ the 5-year cumulative incidence rate and number needed to rescreen for advanced neoplasia in low-risk patients were lower than the 3-year rate and number needed to rescreen of high-risk patients (incidence: 8.5\% vs 14.9\%; number needed to rescreen: 
11.7 vs 6.7). Therefore, our results indicate that patients with a high-risk finding should have a 3-year follow-up colonoscopy and patients without high-risk findings should have a followup colonoscopy in 5 or more years. ${ }^{1-6,19,21,22}$ However, in patients with 3-4 baseline high-risk findings, the 1- and 2-year cumulative incidence rates were $8.0 \%$ and 15.3\%, and number needed to rescreen at 1 and 2 years were 6.6 and 12.5, respectively.

The possible causes of the increased risk of metachronous advanced neoplasia as the baseline high-risk finding increases can be explained by the fact that some lesions are missed or incompletely removed during the baseline colonoscopy. Evidence from back-to-back colonoscopy studies suggests the polyp miss rate is influenced by the number of polyps detected on baseline colonoscopy. ${ }^{25,26}$ In addition, there is a risk of residual neoplastic tissue after resection of large sessile polyps, which may progress and be detected as metachronous advanced lesions in future colonoscopies. In a study of patients with large sessile polyps (>2 cm), 17.6\% had residual adenomatous tissue when reexamined. ${ }^{27}$ In response to this, the British Society of Gastroenterology recommends that patients with $>5$ small adenomas or $\geq 3$ with at least one $\geq 10 \mathrm{~mm}$ undergo repeat colonoscopy at 1 year. ${ }^{28}$ Another possible reason for the higher risk of metachronous advanced neoplasia in patients with multiple risk factors is the possibility of a high-risk milieu for the development of colonic neoplasia and metachronous advanced lesions in particular. ${ }^{29,30}$

We performed a comprehensive literature search to verify our analysis. The literature search was conducted using PubMed and the Cochrane Library for potentially relevant articles published from 2000 to 2011. The following terms were used for the primary search: "Colonoscopy" AND ("colorectal" OR "colonic" OR “colon” OR "large intestine”) AND (“neoplasms” OR “polyp” OR "adenoma" OR "cancer"). Studies meeting the following criteria were included: (1) English language, (2) full-manuscript publication, (3) study design: clinical trials including randomized controlled trials, cohort studies, cross-sectional studies and casecontrol studies. A total of 664 articles were identified using this search strategy; 47 concerned the incidence or risk of metachronous advanced neoplasia in patients with prior polypectomy; 4 of these 47 concerned the incidence or risk of metachronous advanced neoplasia in relation to multiple baseline high-risk findings. ${ }^{10-13}$

The results of these studies cannot be combined into a single estimate in relationship to overlapping multiple baseline highrisk findings because of the differences in baseline high-risk findings of each study. In addition, these studies were confounded by variations in definitions, inclusion and exclusion criteria, design, timing of surveillance intervals, and analysis of endpoints. However, all studies reported that overlapping multiple high-risk findings corresponded to an increase in the risk of metachronous advanced colorectal neoplasia although the high-risk findings were not consistent nor standardized. ${ }^{9-14}$ In a publication by Noshirwani et al., ${ }^{12}$ the percent incidence of advanced neoplasia was calculated using specified numeric combinations of baseline size and number: patients with $\geq 4$ adenomas and at least 1 adenoma $\geq 1 \mathrm{~cm}$ at baseline had a $34.5 \%$ chance of having at least 1 advanced neoplasia within 3.5 years of their initial examination. Nusko et al. ${ }^{11}$ compared the probabilities of advanced metachronous adenoma between 16 subgroups as defined by combinations of multivariate identified risk factors. The probability of being free of advanced metachronous colorectal adenomas 3 years after the initial colonoscopy for the lowest-risk group was 0.964 , whereas the probability of the highest-risk group was 0.777 . Bonithon-Kopp et al. ${ }^{13}$ analyzed data from a chemoprevention trial and reported that the 3-year recurrence rate of advanced adenoma was 28.3\% in patients with $\geq 3$ adenomas with at least 1 located in the proximal colon. In addition, Yamaji et al. ${ }^{10}$ analyzed data from participants in an annual colonoscopic screening program and reported that the annual incidence rate of advanced colorectal lesions was higher in patients with multiple risk factors such as older age, male sex, and advanced lesions at baseline.

The proximal polyp was reported as a high risk finding for metachronous advanced colorectal neoplasia. Among 862 recruited patients, 573 patients had one or more adenoma located in the proximal colon (cecum to splenic flexure). The Cox regression model found that the proximal polyp was a significant risk factor for metachronous advanced colorectal neoplasia (univariate analysis: HR, 1.26, 95\% CI, 1.48 to 3.44; multivariate analysis: HR, 2.10, 95\% CI, 1.36 to 3.25 ). However, the percent of patients with one or more proximal adenoma was as high as $66.5 \%$ and the practice guideline was not recommended as a risk factor for metachronous advanced colorectal neoplasia. Therefore, we did not consider the proximal adenoma as a highrisk finding. In addition, a family history of colorectal cancer is one of the risk factors of colorectal neoplasia development. However, according to the practice surveillance guideline, the surveillance interval was not shortened by a family history of colorectal cancer.

The serrated polyps more than $1 \mathrm{~cm}$ or located in the proximal colon are one of the high risk findings for metachronous advanced colorectal neoplasia. However, the concept of a serrated pathway was introduced in 2003 and established after 2010 (The current classification of serrated polyps is based on the fourth addition of the WHO book published in 2010). ${ }^{15}$ During the patients' recruitment period, hyperplastic polyps considered as nonneoplastic lesion. Therefore, some hyperplastic polyps were not removed completely, even though some hyperplastic polyps were measured to be more than $1 \mathrm{~cm}$ in size and located in the proximal colon. Therefore, serrated polyps more than 1 $\mathrm{cm}$ or located in the proximal colon were not defined as high risk findings.

Our study has several limitations. First, the retrospective analysis prevented the evaluation of important factors that af- 
fect the quality of the colonoscopy, including family history, past medical history, bowel preparation status, cecal intubation rate, withdrawal time, and adenoma detection rates of the endoscopists. Secondly, most patients labeled as high-risk had multiple polyps, which increases the chance of a missed lesion. Thirdly, patients with a single advanced adenoma had shorter follow-up intervals given their increased risk for interval cancer and advanced adenoma due to incomplete resection. Fourthly, this study analyzed data from a single referral center, which means that the patients had a higher proportion of advanced adenoma and multiple risk factors than the general population. Finally, in the real world situation, the surveillance interval may be affected by the quality of the baseline examination and completeness of the polypectomy, as well as the patient's concern or preference. Because of the limitation of the retrospective study, the surveillance interval was different from the recommended intervals. However, the cumulative incidence of advanced neoplasia was similar between the first follow-up colonoscopy $<2$ and $\geq 2$ years. In addition, irrespective of the first follow-up colonoscopy time, the overlapping multiple high-risk findings were associated with further increased risk of advanced neoplasia during surveillance.

In summary, multiple high-risk findings were associated with increased risk of advanced neoplasia during surveillance. Although our findings generally support the surveillance recommendations of the current guidelines, we additionally recommend that patients with high-risk findings be grouped according to the number of findings, and that patients with 3-4 baseline high-risk findings undergo surveillance within 5 years. Further multicenter prospective studies are needed to confirm our findings and to determine the optimal surveillance interval in patients with multiple high-risk findings on baseline colonoscopy. Additionally, future studies are required to further stratify those we currently consider to be at high risk of metachronous advanced neoplasia, and to determine the cost-effectiveness of surveillance strategies.

\section{CONFLICTS OF INTEREST}

No potential conflict of interest relevant to this article was reported.

\section{ACKNOWLEDGEMENTS}

This study was supported by Samsung Biomedical Research Institute grant (SMX1132051).

\section{REFERENCES}

1. Winawer SJ, Zauber AG, Fletcher RH, et al. Guidelines for colonoscopy surveillance after polypectomy: a consensus update by the US Multi-Society Task Force on Colorectal Cancer and the
American Cancer Society. Gastroenterology 2006;130:1872-1885.

2. Davila RE, Rajan E, Baron TH, et al. ASGE guideline: colorectal cancer screening and surveillance. Gastrointest Endosc 2006;63: 546-557.

3. Schmiegel W, Pox C, Arnold D, et al. Colorectal carcinoma: the management of polyps, (neo)adjuvant therapy, and the treatment of metastases. Dtsch Arztebl Int 2009;106:843-848.

4. Bond JH. Polyp guideline: diagnosis, treatment, and surveillance for patients with colorectal polyps. Practice Parameters Committee of the American College of Gastroenterology. Am J Gastroenterol 2000;95:3053-3063.

5. Arditi C, Peytremann-Bridevaux I, Burnand B, et al. Appropriateness of colonoscopy in Europe (EPAGE II): screening for colorectal cancer. Endoscopy 2009;41:200-208.

6. Hong SN, Yang DH, Kim YH, et al. Korean guidelines for postpolypectomy colonoscopic surveillance. Korean J Gastroenterol 2012;59:99-117.

7. Martínez ME, Baron JA, Lieberman DA, et al. A pooled analysis of advanced colorectal neoplasia diagnoses after colonoscopic polypectomy. Gastroenterology 2009;136:832-841.

8. Saini SD, Kim HM, Schoenfeld P. Incidence of advanced adenomas at surveillance colonoscopy in patients with a personal history of colon adenomas: a meta-analysis and systematic review. Gastrointest Endosc 2006;64:614-626.

9. Yang G, Zheng W, Sun QR, et al. Pathologic features of initial adenomas as predictors for metachronous adenomas of the rectum. $\mathrm{J}$ Natl Cancer Inst 1998;90:1661-1665.

10. Yamaji Y, Mitsushima T, Ikuma H, et al. Incidence and recurrence rates of colorectal adenomas estimated by annually repeated colonoscopies on asymptomatic Japanese. Gut 2004;53:568-572.

11. Nusko G, Mansmann U, Kirchner T, Hahn EG. Risk related surveillance following colorectal polypectomy. Gut 2002;51:424-428.

12. Noshirwani KC, van Stolk RU, Rybicki LA, Beck GJ. Adenoma size and number are predictive of adenoma recurrence: implications for surveillance colonoscopy. Gastrointest Endosc 2000;51(4 Pt 1): 433-437.

13. Bonithon-Kopp C, Piard F, Fenger C, et al. Colorectal adenoma characteristics as predictors of recurrence. Dis Colon Rectum 2004;47:323-333.

14. Atkin WS, Morson BC, Cuzick J. Long-term risk of colorectal cancer after excision of rectosigmoid adenomas. N Engl J Med 1992; 326:658-662.

15. Snover DC, Ahnen DJ, Burt RW, et al. Serrated polyps of the colon and rectum and serrated ('hyperplastic') polyposis. In: Bosman FT, World Health Organization; International Agency for Research on Cancer, eds. WHO classification of tumours of the digestive system. 4th ed. Lyon: International Agency for Research on Cancer, 2010.

16. Boolchand V, Olds G, Singh J, Singh P, Chak A, Cooper GS. Colorectal screening after polypectomy: a national survey study of primary care physicians. Ann Intern Med 2006;145:654-659.

17. Tanaka S, Obata D, Chinzei R, et al. Surveillance after colorectal 
polypectomy: comparison between Japan and U.S. Kobe J Med Sci 2011;56:E204-E213.

18. Hong SN, Yang DH, Kim YH, et al. A survey for post-polypectomy surveillance. Intest Res 2011;9:118-128.

19. Winawer SJ, Zauber AG, O'Brien MJ, et al. Randomized comparison of surveillance intervals after colonoscopic removal of newly diagnosed adenomatous polyps: the National Polyp Study Workgroup. N Engl J Med 1993;328:901-906.

20. Jørgensen OD, Kronborg O, Fenger C. A randomized surveillance study of patients with pedunculated and small sessile tubular and tubulovillous adenomas: the Funen Adenoma Follow-up Study. Scand J Gastroenterol 1995;30:686-692.

21. Lieberman DA, Weiss DG, Harford WV, et al. Five-year colon surveillance after screening colonoscopy. Gastroenterology 2007;133: 1077-1085.

22. Chung SJ, Kim YS, Yang SY, et al. Five-year risk for advanced colorectal neoplasia after initial colonoscopy according to the baseline risk stratification: a prospective study in 2452 asymptomatic Koreans. Gut 2011;60:1537-1543.

23. Kim CJ, Jung YS, Park JH, et al. Prevalence, clinicopathologic characteristics, and predictors of interval colorectal cancers in Korean population. Intest Res 2013;11:178-183.

24. Hong SP, Kim TI, Kim HG, et al. Clinical practice of surveillance colonoscopy according to the classification of colorectal intraepithelial neoplasia in Korea: high-grade dysplasia/carcinoma in situ versus intramucosal carcinoma. Intest Res 2013;11:276-282.

25. Leufkens AM, van Oijen MG, Vleggaar FP, Siersema PD. Factors influencing the miss rate of polyps in a back-to-back colonoscopy study. Endoscopy 2012;44:470-475.

26. Kim JH, Kim YS, Cheon JH, et al. Influence of the insertion time and number of polyps on miss rate in colonoscopy. Scand J Gastroenterol 2011;46:634-639.

27. Lieberman DA, Rex DK, Winawer SJ, et al. Guidelines for colonoscopy surveillance after screening and polypectomy: a consensus update by the US Multi-Society Task Force on Colorectal Cancer. Gastroenterology 2012;143:844-857.

28. Cairns SR, Scholefield JH, Steele RJ, et al. Guidelines for colorectal cancer screening and surveillance in moderate and high risk groups (update from 2002). Gut 2010;59:666-689.

29. Arain MA, Sawhney M, Sheikh S, et al. CIMP status of interval colon cancers: another piece to the puzzle. Am J Gastroenterol 2010;105:1189-1195.

30. Sawhney MS, Farrar WD, Gudiseva S, et al. Microsatellite instability in interval colon cancers. Gastroenterology 2006;131:17001705. 